\title{
A IMPORTÂNCIA DA EDUCAÇÃO AMBIENTAL PARA O ENSINO MÉDIO
}

\author{
Maria Aparecida de Sá ${ }^{1}$ \\ Marcondes Albuquerque de Oliveira ${ }^{2}$ \\ Ana Selia Rodrigues Novaes ${ }^{3}$
}

Resumo: Preservação, conservação, desenvolvimento sustentável, qualidade de vida, são conceitos que devem fazer parte do nosso cotidiano. Diante disto, foi realizada uma pesquisa descritiva, tendo como objetivo analisar como os professores das Escolas Públicas Estaduais de Floresta - PE vem trabalhando as questões ambientais e com qual frequência nas turmas de Ensino Médio. Foi utilizado o estudo de caso através de questionários para os alunos do Ensino Médio, professores e gestores das escolas públicas estaduais da cidade de Floresta - PE, com amostragem aleatória de 10\% dos alunos; $30 \%$ dos educadores do Ensino Médio e os gestores de cada escola pesquisada. Foi constatado que as escolas pesquisadas ainda não realizam um trabalho eficiente com relação às questões ambientais.

Palavras-chave: Educação Ambiental; Meio Ambiente; Sustentabilidade.

1IF SERTÃO - PE Campus Floresta. E-mail: cidasa66@hotmail.com

${ }^{2}$ Instituto de Tecnologia de Pernambuco - ITEP. E-mail: marcondesoliveira@hotmail.com

${ }^{3}$ IF SERTÃO - PE Campus Petronila Zona Rural. E-mail: anaselianovaes@hotmail.com 


\section{Introdução}

A Educação Ambiental pode ser entendida como toda ação educativa que contribui para a formação de cidadãos conscientes da preservação do meio ambiente e apto a tomarem decisões coletivas sobre questões ambientais necessárias para o desenvolvimento de uma sociedade sustentável. É o instrumento eficaz para se conseguir criar e aplicar formas sustentáveis de interação sociedade-natureza. Este é o caminho para que o indivíduo assuma novas atitudes que levem a diminuição da degradação ambiental, promova a melhoria da qualidade de vida e reduza a pressão sobre os recursos naturais.

Sabe-se que, numa sociedade, a escola é considerada o centro de formação humana e profissional do cidadão, e ao lado da família e dos meios de comunicação compartilha a responsabilidade de desenvolver as habilidades e 0 acesso à informação.

Diante disso, a Educação Ambiental está relacionada com as áreas de pesquisa, análise, apresentação e conscientização a respeito das necessidades e obrigações com o meio ambiente e com o aprofundamento do conhecimento sobre o mesmo, preparando o ser humano para a preservação da natureza e para o uso sustentável de seus recursos.

Portanto, Educação Ambiental deve ser vista como um processo de permanente aprendizagem que valoriza as diversas formas de conhecimentos, habilidades e competências, visando formar cidadãos comprometidos com a melhoria local e planetária. À medida que adquire novos conhecimentos, o educando, se torna mais capaz de interagir melhor com os seus semelhantes e com o espaço geográfico.

Dessa forma, o aprender deve ser um ato de formação contínua, e o termo desenvolvimento sustentável é empregado nessa estratégia com o significado de melhorar a qualidade de vida humana dentro dos limites da capacidade de suporte dos ecossistemas. Para tanto, é importante o fortalecimento das organizações sociais e comunitárias, a redistribuição de recursos mediante parcerias, de informação e capacitação para participar crescentemente dos espaços públicos de decisão e para a construção de instituições pautadas por uma lógica de sustentabilidade.

O desafio político da sustentabilidade, apoiado no potencial transformador das relações sociais que representam o processo da Agenda 21, encontra-se estreitamente vinculado ao processo de fortalecimento da democracia e da construção da cidadania.

A Educação Ambiental, nas suas diversas possibilidades, abre um estimulante espaço para repensar práticas sociais e o papel dos professores como mediadores e transmissores de um conhecimento necessário para que os alunos adquiram uma base adequada de compreensão essencial do meio ambiente global e local, da independência dos problemas e soluções e da 
importância da responsabilidade de cada um para construir uma sociedade planetária mais equitativa e ambientalmente sustentável.

\section{O trabalho com a Educação Ambiental}

A Educação Ambiental é considerada hoje um processo permanente, no qual os indivíduos e a comunidade tomam consciência do meio ambiente e adquirem os conhecimentos, os valores, as habilidades, as experiências e a determinação que os tornam aptos a agir individual e coletivamente para resolver problemas ambientais presentes e futuros.

De acordo com a Lei 9.795/99, entende-se por Educação Ambiental os processos por meio dos quais o indivíduo e a coletividade constroem valores sociais, conhecimentos, habilidades, atitudes e competências voltadas para a conservação do meio ambiente, bem de uso comum do povo, essencial à sadia qualidade de vida e sua sustentabilidade (BRASIL, 2007).

Uma das alternativas para a inclusão da temática ambiental no meio escolar é a aprendizagem em forma de projetos, essa é uma proposta alinhada com o novo entendimento do processo de aprendizagem que sugere a necessidade de estratégias de ensino mais adequadas e torna evidente a importância de um currículo integrado que valorize o conhecimento contextual, no qual as várias disciplinas sejam vistas como recursos a serviço de um objeto central. Esse objeto central também pode ser entendido como um tema transversal que permeia as outras disciplinas já constituídas e consegue trazer para a realidade escolar o estudo de problemas do dia a dia.

A Educação Ambiental é um instrumento essencial para poder melhorar os impactos ambientais que tanto vem prejudicando o nosso dia a dia, ela exerce um papel fundamental na formação crítica e atuante dos nossos indivíduos no qual desenvolve uma sociedade de consumo consciente, no intuito de preservar o mesmo.

O aprendizado ambiental é um componente vital, pois oferece motivos que levam os alunos se reconhecerem como parte integrante do meio em que vivem e faz pensar nas alternativas para soluções dos problemas ambientais e ajudar a manter os recursos para as futuras gerações.

O princípio da sustentabilidade, segundo Leff (2008), surge no contexto da globalização como a marca de um limite e o sinal que reorienta o processo civilizatório da humanidade. A crise ambiental veio questionar a racionalidade $e$ os paradigmas teóricos que impulsionaram e legitimaram o crescimento econômico, negando a natureza. A sustentabilidade ecológica é um suporte eficaz para se chegar a um desenvolvimento duradouro, questionando as próprias bases de produção.

Os seres humanos são os únicos animais que transformam a natureza em benefício de sua sobrevivência. No entanto, para atender às necessidades atuais, estamos usando nossa capacidade de modo a tornar o ambiente insustentável para as gerações futuras. Não podemos transformar, sem limites, 
a natureza. Somos muitos, os recursos da Terra finitos, e nossa tecnologia causa fortes impactos no ambiente: polui o ar e a água, altera o solo, destrói florestas e outros ambientes naturais, transforma a atmosfera, modifica o clima. Não é mais possível explorar ilimitadamente os elementos da natureza e causar tantos impactos ambientais (CARVALHO et al.,2008).

O meio ambiente vem sofrendo grande perda com toda essa produção acelerada e esse consumo desenfreado. É essencial que o ser humano entenda a necessidade de cuidar do ambiente uma vez que toda sobrevivência existente é adquirida através dos recursos oferecidos e que para se formar cidadãos atuantes é preciso formar a consciência dos mesmos e transforma-se em filosofia de vida. A Educação Ambiental, deve necessariamente transforma-se em ação.

\section{Metodologia utilizada na Pesquisa de Campo}

Tendo em vista a grande preocupação com o Meio Ambiente, esta pesquisa foi realizada com o objetivo de descobrir como as escolas estaduais de Floresta - PE vêm trabalhando as questões ambientais ao mesmo que buscou esclarecer e conscientizar gestores, professores e alunos sobre a importância de se trabalhar a Educação Ambiental em todo cotidiano escolar fazendo-se enxergar que a fonte de todos os recursos necessários para se viver estar bastante ameaçado devido ao consumo desenfreado e as novas tecnologias da população podendo levar o meio ambiente a destruição.

A Educação Ambiental permite que o processo pedagógico aconteça sob diferentes aspectos, que se complementam uns aos outros. Assim, há um espaço para momentos onde ocorre transmissão de conhecimento, construção do conhecimento e a desconstrução das representações sociais. Com a Educação Ambiental, a escola, os conteúdos e o papel do professor e dos alunos são colocados em uma nova situação, não apenas relacionada com o conhecimento, mas sim com o uso que fazemos dele e sua importância para a nossa participação política cotidiana.

Portanto, cabe a escola contribuir para o processo de transformação da sociedade atual em uma sociedade sustentável, centrando no exercício responsável da cidadania, que considere a natureza como um bem comum, leve em conta a capacidade de regeneração dos recursos materiais, promova a distribuição equitativa da riqueza gerada e favoreça condições dignas de vida para as gerações atuais e futuras.

O trabalho iniciou-se com estudos, pesquisas bibliográficas e confecções de resumos para que se pudesse entender mais sobre a questão da Educação Ambiental, fazendo-se um recorte teórico do que seria necessário para aplicação do mesmo. Diante disto, a realização desta pesquisa foi descritiva com abordagem qualiquantitativa onde remeteu para verificação de como se dar o processo de ensino e aprendizagem no que diz respeito à questão ambiental e a sustentabilidade nas turmas de ensino médio das escolas públicas estaduais 
de Floresta. O questionário, do tipo questões objetivas foi o instrumento para a coleta de dados. O sujeito ao qual se destinou a pesquisa preencheu um termo de consentimento livre e esclarecido.

A população investigada é formada por professores, gestores e alunos das escolas públicas estaduais de Floresta - PE, e foi obtida uma amostragem de $10 \%$ dos alunos e $30 \%$ dos educadores e gestores de cada escola pesquisada, num total de quatro escolas da sede, após conversa com os mesmos para esclarecer sobre a pesquisa, sua finalidade e importância. A coleta de dados foi analisada e separada de acordo com cada grupo: gestores, professores e alunos.

Após análise dos dados foram socializados os resultados obtidos em um seminário realizado no Auditório do IF Sertão Pernambucano, Campus Floresta, com a presença de representação de todos os segmentos participantes da pesquisa, na ocasião foi distribuído panfletos informativos sobre os cuidados que devemos ter com os recursos naturais e todas as questões ambientais.

\section{Resultados e Discussões}

Na pesquisa realizada com os gestores das quatro escolas, todos afirmam que a Educação Ambiental deve ser trabalhada diariamente, que em suas escolas realizam momentos de reflexão sobre o tema, e que realizam atividades de incentivo sobre a sustentabilidade e a preservação ambiental.

Com relação a metodologia utilizada pelos professores tem colaborado com o processo de Educação Ambiental, houve variações de respostas, conforme Figura 1.

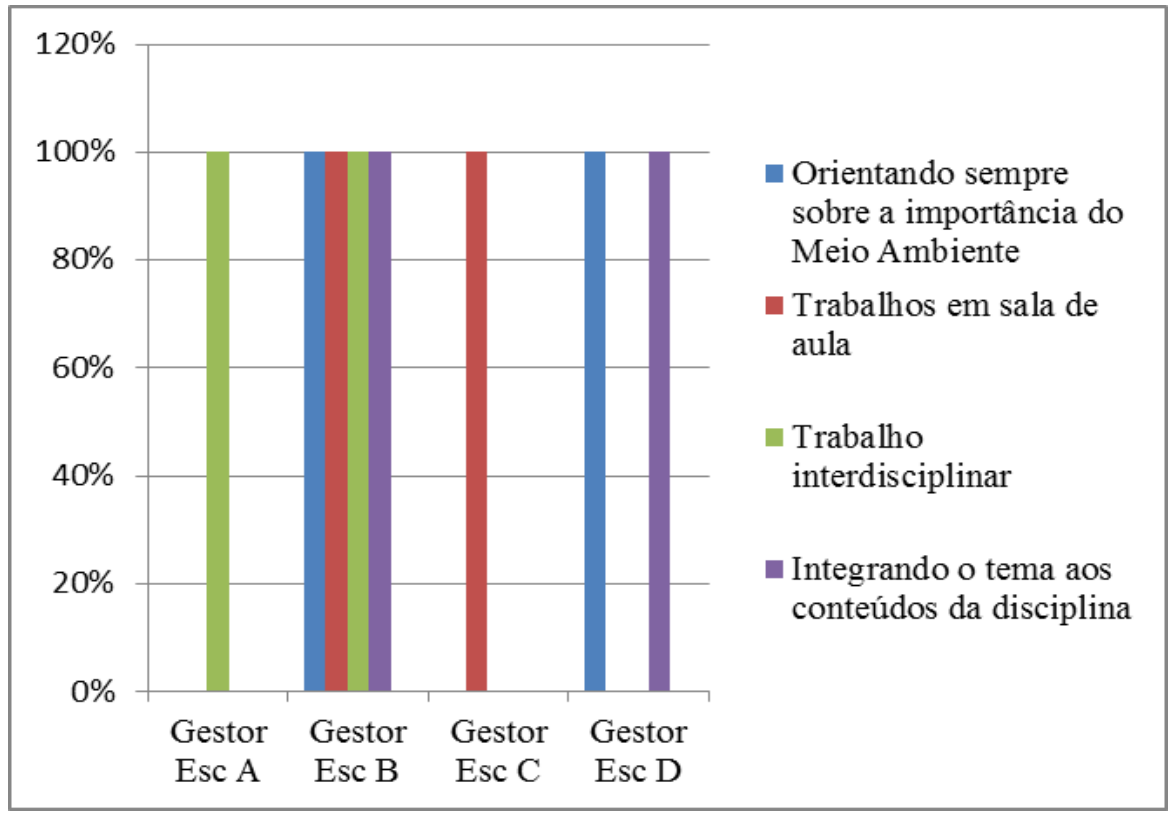

Figura 1: Como os gestores percebem como a metodologia utilizada pelos professores tem contribuído com o Processo de Educação Ambiental. Fonte: Autores. 
Quanto à reciclagem, os gestores das Escolas $\mathrm{B}$ e $\mathrm{D}$ dizem que realizam a separação dos resíduos para reciclagem, já os das Escolas $A$ e $C$ não realizam separação. Os gestores das Escolas A, C e D, confessam que tem contribuído a nívellocal, regional e global com as questões ambientais, incentivando os servidores a participar de atividades de mobilização, enquanto que o gestor da Escola B diz que organiza oficinas e palestras relacionadas ao Meio Ambiente e Sustentabilidade. Os gestores colocam ainda que o Projeto Cultura de Paz, promovido pela Diocese de Floresta, proporcionou métodos para trabalhar a Educação Ambiental, facilitando o trabalho dos professores referentes ao tema.

$\mathrm{Na}$ opinião da maioria dos professores, a Educação Ambiental deve ser trabalhada diariamente, apenas alguns se posicionam argumentando que basta que seja mensalmente. Em todas as escolas pesquisadas, os professores dizem que a escola na qual eles estão lotados realiza momentos para reflexão relacionada ao tema ambiental, coincidindo com as respostas dos gestores.

Os professores da Escola $A, B$ e $C$ relatam que sempre têm desempenhado seu trabalho contextualizando-o com ideias sustentáveis e a importância da preservação do Meio Ambiente, apenas os professores da Escola D dizem que as vezes fazem essa contextualização.

Todos os professores das escolas pesquisadas relatam que a escola onde trabalham realiza atividades de incentivo a sustentabilidade e a preservação ambiental. Ao serem indagados como a metodologia dos professores tem colaborado com o processo de Educação Ambiental, houve variações de respostas conforme Figura 2.

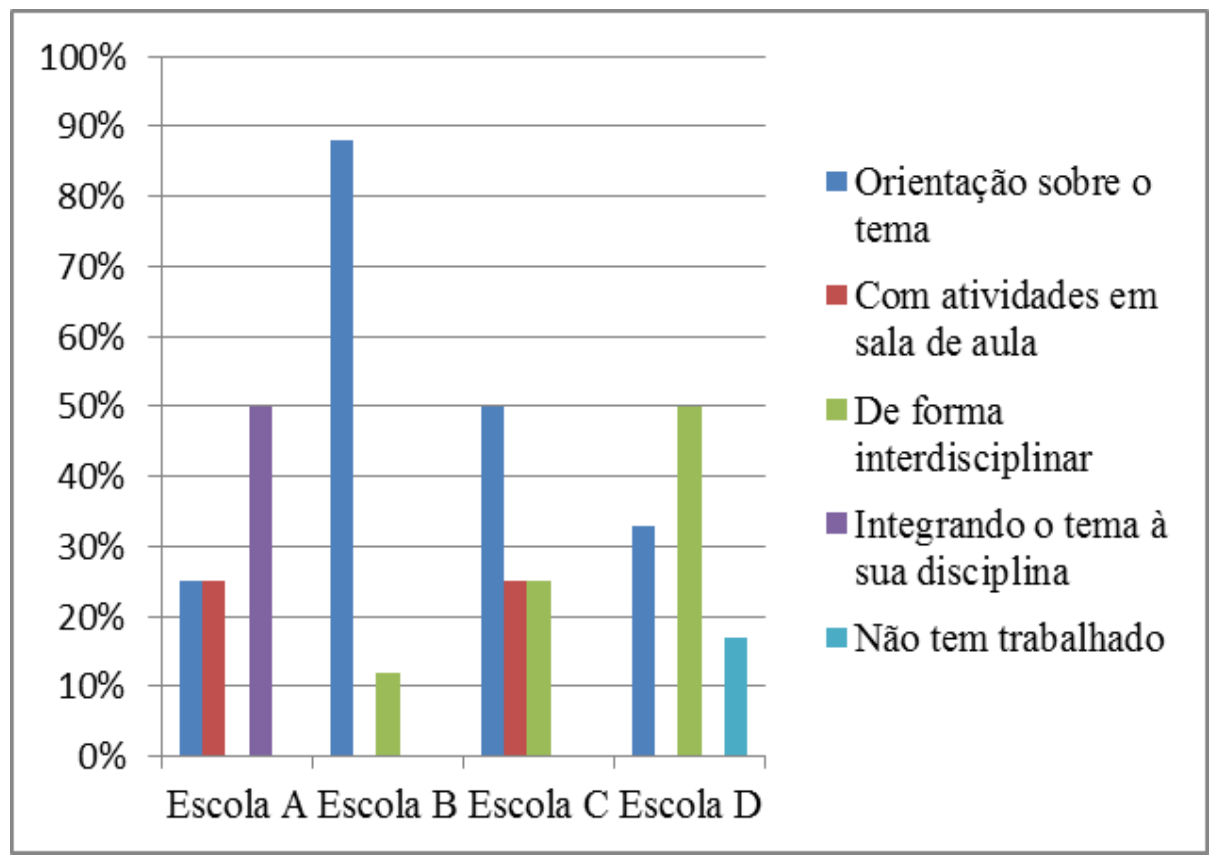

Figura 2: Como os professores vêm de que forma a metodologia utilizada por eles tem contribuído com o Processo de Educação Ambiental. Fonte: Autores. 
Quanto à reciclagem, $50 \%$ dos professores dizem que a escola não realiza a separação dos resíduos, e os outros $50 \%$ respondem que a escola realiza a separação, mas eles desconhecem o destino destes resíduos.

Em se tratando das contribuições que os professores têm dado em relação ao Meio Ambiente e a Sustentabilidade a nível local, regional e global, surge algumas ações colocadas por eles, como: realização de projetos com o tema; contextualização do tema com a disciplina; e organização de atividades de mobilização junto a escola.

A maioria dos professores afirma que o Projeto Cultura de Paz promovido pela Diocese de Floresta, facilitou o seu trabalho em relação às questões ambientais.

Em se tratando das respostas dos alunos, $90 \%$ dizem que entende por Educação Ambiental, como sendo uma prática sobre o meio ambiente para a construção de uma sociedade sustentável. $60 \%$ relatam que a escola onde estudam incentiva práticas que levam a construção de valores socioambientais, enquanto que $40 \%$ não tem percebido este incentivo.

As atividades que a escola tem desenvolvido a cerca do tema, no sentido de motivar os alunos a preservar o meio ambiente, segundo $75 \%$ dos alunos têm sido atividades em sala de aula, de forma contextualizada, os demais dizem que através de palestras e oficinas.

Divergindo das respostas dos gestores e dos professores, $80 \%$ dos alunos das quatro escolas pesquisadas afirmam que a sua escola não realiza a separação dos resíduos, os demais não sabem, nunca viu. Os alunos relatam que nunca expôs nenhuma ideia para contribuir para a sustentabilidade.

A maioria dos alunos afirma já terem trabalhado com algum tipo de reciclagem com algum tipo de material, dentre eles (Figura 3).

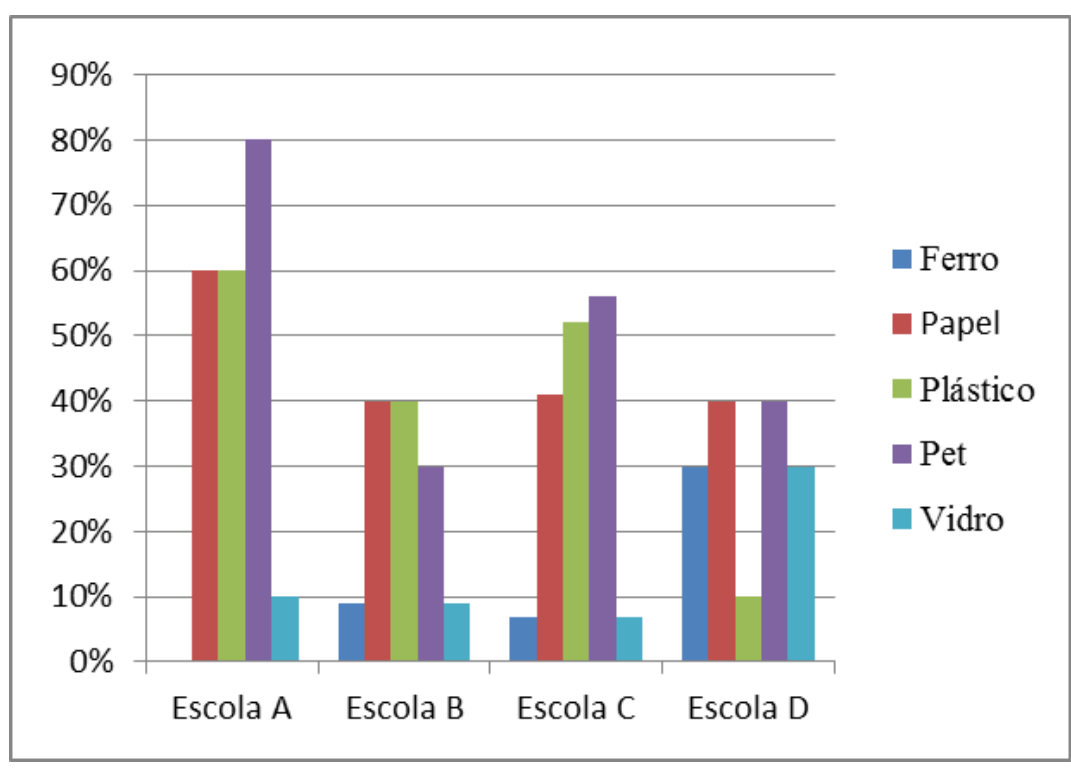


Todos os alunos pesquisados reconhecem a importância de se trabalhar às questões ambientais e a sustentabilidade, através de projetos com um trabalho interdisciplinar, diariamente. Ressaltam ainda, que conhecem o Projeto Cultura de Paz e acreditam que o mesmo trouxe contribuições importantes, facilitando o trabalho dos professores.

Percebe-se que as escolas envolvidas acreditam que a Educação Ambiental deve estar presente em todo cotidiano escolar para que os alunos aprendam sobre a necessidade de atribuir e construir novos valores voltados ao meio ambiente, tornando assim, cidadãos socioambientais, afirmam ainda que o tema está sendo trabalhado diariamente junto à disciplina de cada professor.

A questão é que esses dados colhidos mostraram que há controvérsia entre os gestores/professores e alunos. Enquanto os gestores e professores dizem fazer sempre trabalhos voltados a questão ambiental no dia a dia no ambiente escolar, parte dos alunos afirma não ocorrer este trabalho.

Os alunos apresentaram grande interesse sobre a Educação Ambiental e desenvolvimento sustentável, porém observa-se que a carência do tema é bastante, mesmo com a obrigatoriedade da Lei oㅜ 9.795/99 que estabelece que a Educação Ambiental deva estar presente, de forma articulada, em todos os níveis e modalidades do processo educativo, ainda há uma grande precariedade, pois a Lei e realidade andam longe uma da outra.

\section{Conclusões}

Na pesquisa realizada observa-se que parte dos alunos do Ensino Médio das Escolas Estaduais de Floresta - PE tem uma noção sobre a questão Ambiental. No entanto, percebe-se que gestores e professores dificilmente saem do discurso e partem para prática, há uma grande carência em projetos voltados ao meio ambiente e em continuações de trabalhos relacionados ao tema.

Entende-se ainda que, a maioria dos alunos tem interesse em aprender mais sobre Educação Ambiental. Sendo necessário afirmar que os gestores/professores tem clareza quanto à importância dessa temática, mas pouca consistência em relação à mesma. Percebe-se a necessidade de se incentivar diariamente na escola reflexões e práticas que levem todos a compreender as questões ambientais, para que se possam formar cidadãos com consciência ambiental, facilitando assim, sua vivência em sociedade.

Conclui-se que o caminho para que cada indivíduo mude de hábitos e assuma novas posturas que levem à diminuição da degradação ambiental, promovam a melhoria da qualidade de vida e reduzam a pressão sobre os recursos ambientais só será possível com a vivência de práticas educativas, ou seja, através da Educação Ambiental. 


\section{AGRADECIMENTOS}

Ao Instituto de Tecnologia de Pernambuco - ITEP e ao Instituto Federal de Educação, Ciência e Tecnologia do Sertão Pernambucano - IFSERTÃO-PE pela oportunidade de ter nos proporcionado o Curso de Mestrado em Tecnologia Ambiental.

\section{REFERÊNCIAS}

BRASIL, Lei no 9.795 de 27 de abril de 1999. Dispõe sobre Educação Ambiental, institui a política nacional de Educação Ambiental e dá outras providências. Brasília: MEC, 2007.

CARVALHO, A. et al. Jovens em ação! Ações para melhorar o ambiente e a qualidade de vida nas cidades. São Paulo: Melhoramentos, 2008.

LEFF, H. Saber Ambiental: Sustentabilidade, Racionalidade, Complexidade, Poder. 3. Ed. Rio de Janeiro: Vozes, 2008. 